\title{
OPTIMISM WITHOUT THEISM? NAGASAWA ON ATHEISM, EVOLUTION, AND EVIL
}

\author{
Guy Kahane, University of Oxford
}

\begin{abstract}
Nagasawa has argued that the suffering associated with evolution presents a greater challenge to atheism than to theism because that evil is incompatible with 'existential optimism' about the world-with seeing the world as an overall good place, and being thankful that we exist. I argue that even if atheism was incompatible with existential optimism in this way, this presents no threat to atheism. Moreover, it's unclear how the suffering associated with evolution could on its own undermine existential optimism. Links between Nagasawa argument and the current debate about the axiology of (a)theism are also explored.
\end{abstract}

\section{INTRODUCTION}

Many atheists hold that the massive amount of suffering and early death associated with evolution-suffering and death that is undeserved, nor due to anyone's free choice-is a powerful reason to doubt that God exists. Yujin Nagasawa has recently proposed, however, that the existence of such natural evil is actually a greater threat to atheism. ${ }^{1}$ If successful, Nagasawa's argument would blow apart a central strand of the case for atheism. In the first part of this paper, I'll offer an interpretation of Nagasawa's new 'existential problem of evolutionary evil'. Nagasawa argues that past evolutionary suffering presents a challenge to what he calls 'existential optimism' - the view that the world is overall good, and that we should be thankful for our existence - and that because this challenge is greater for atheists, this should motivate them to endorse theism. I'll argue first that even if atheism turned out to be incompatible with existential optimism in this way, this presents no threat to atheism as such. It would still be important, however, if atheism would force us to give up existential optimism - if, coupled with familiar facts about evolutionary history, atheism — or more precisely, metaphysical naturalism - entails a dark view of the universe we inhabit. ${ }^{2}$ But I'll argue that the suffering associated with evolution cannot on its own show that the world isn't overall good, under a natural interpretation of that axiological claim. In fact, we shall see that, if God doesn't exist, we're simply not in an epistemic position to endorse such claims. It's nevertheless possible that the naturalistic universe, or even just life here on little Earth, would end up being overall bad. That would be a bleak result. But I'll argue that, unlike more familiar forms of philosophical pessimism, such global pessimism won't dramatically change our lives, or rule out feeling gratitude for our existence. I'll argue moreover, that although it's 
plausible that, if theism is true, the world would be overall good (and even exceedingly so), this isn't a conceptual truth; it's a substantive axiological claim that requires defence. I'll conclude by discussing the relation between arguments from atheism to pessimism and the comparative questions that have so far been the focus of the axiology of (a)theism.

\title{
NAGASAWA'S EXISTENTIAL PROBLEM OF EVOLUTIONARY EVIL
}

Richard Dawkins once remarked that

\begin{abstract}
"We have cause to give thanks for our highly improbable existence, and the law-like evolutionary processes that gave rise to it."3
\end{abstract}

Elsewhere, Dawkins offered a gloomier view of evolution, saying that

"[N]atural selection is out there and it is a very unpleasant process. Nature is red in tooth and claw. But I don't want to live in that kind of a world..."4

Nagasawa suggests that Dawkins's two remarks illustrate two inconsistent commitments held by many atheists.

One of these commitments is expressed in Dawkins's remark about the unpleasantness of natural selection. That's an understatement since the process of natural selection involved the suffering and death of trillions of sentient beings, over many hundreds of millions of years. That's already a massive amount of evil, or, better, badness, but Nagasawa suggests that evolution is associated with an evil that is over and above that first-order badness. Nagasawa calls this 'systemic evil'. We shall explore this idea later.

For now, though, let us state this commitment as

Evolutionary Evil (EE). Terrestrial evolutionary history contains a vast amount of badness (and evolution may also be a systemic evil).

The second commitment is supposed to be expressed by the Dawkins's first remark. Nagasawa calls it Existential Optimism (EO), the thesis that

"The world is, overall, a good place and we should be grateful for our existence in it." 
Nagasawa argues that these two commitments are incompatible. He writes:

"If the "law-like evolutionary processes" guarantee pain and suffering for uncountably many humans and other sentient animals, it seems impossible for atheists like Dawkins to consistently defend existential optimism."

By contrast, while theists may have difficulty explaining why EE is true, Nagasawa argues that they have less difficulty reconciling EE and EO within the theist framework. which is not confined to the natural world, offers greater space for further, supernatural value to overturn whatever deficit EE may generate. ${ }^{7}$

Nagasawa therefore concludes that:

"We normally take for granted that the problem of evil provides a reason to give up theism... Yet... it might be the other way around. The problem of evil, or at least the existential problem of systemic evil, provides a reason to give up atheism and a motivation to adopt theism." 8

Before we assess this argument, we should first ask whether atheists really do have these commitments. Few if any reflective atheists would deny that evolution is associated with massive natural evil: after all, many of them make extensive appeal to that evil in arguing for their atheism. The commitment to Existential Optimism, however, is trickier. This view combines an axiological claim:

Axiological Optimism. The world is, overall, a good place.

and a claim about fitting attitudes:

Attitudinal Optimism. We should be grateful for our existence in the world.

I will focus first on Axiological Optimism. It is natural to interpret it as the claim that the world overall contains more good than bad $^{9}$ - that is after all exactly what pessimists such as Schopenhauer deny. ${ }^{10}$ It's not clear whether by 'world' Nagasawa means that entire cosmos, across space and time, or just what is going on here on Earth. I'll consider both readings here.

Now Nagasawa rightly rejects the idea that all atheists are "negative, nihilistic, pessimistic people who think that life is miserable or absurd" who think that "there is nothing 
about our mortal existence for which we should feel happy or grateful."11 That's obviously true. But that's still a far cry from literal endorsement of Axiological Optimism. In fact, neither Dawkins, nor the other atheists Nagasawa quotes, ${ }^{12}$ says anything that directly expresses commitment to Axiological Optimism. They merely express gratitude for existing. Nagasawa thinks, however, that people like Dawkins wouldn't express gratitude for existing if they thought that there were surrounded by utter misery. He writes,

"Otherwise, their view would be a form of pessimism except about themselves; existential optimism is a worldview, rather than the plain assertion that 'I am happy and grateful to be alive (but I do not know about others)'."13

But as we'll see later, attitudes such as gratitude needn't directly mirror our value judgments about the world and we therefore cannot simply infer the latter from the former. Moreover, we can believe that things are good in ways that go beyond our personal lives without thinking that the world is good, let alone without thinking that about the entire cosmos. It's likely that Dawkins believes that the lives of very many other people are good, or good enough. It's a massive step from that to the conclusion that, say, things on Earth, or even just terrestrial history till now, is overall good. In fact, I'd be surprised if Dawkins, or most people, have interesting views on such grand axiological questions. Agnosticism on such questions isn't a form of pessimism. And, as we shall see below, such agnosticism is also appropriate. ${ }^{14}$ It seems to me doubtful that we can attribute to people a strong commitment to a view they never explicitly endorse and which can be supported by little to no evidence.

\section{AN ARGUMENT AGAINST ATHEISM?}

Setting this aside, we can ask next whether Nagasawa's problem really offers reason to give up atheism. Interpreted as an explicit argument, the key idea seems to be the following:

\section{The Existential Problem of Evolutionary Evil}

(A) Evolutionary Evil (EE): terrestrial evolutionary history contains a vast amount of badness.

(B) The Bleak Upshot: If atheism is true then, because of EE, Existential Optimism (EO) is (probably) false.

(C) It is easier to reconcile theism with EO. 
Therefore,

(D) Atheists who accept EO have reason to give up atheism and adopt theism.

Let us first consider the final step of Nagasawa's argument. ${ }^{15}$ Let us assume for now that, if we assume that atheism is true, then EE and EO are indeed somehow incompatible. Would this give us "a reason to give up atheism and a motivation to adopt theism"?

Notice first that, as the above makes clear, this isn't a general argument against atheism. It's an argument against atheists who also endorse EO, an independent view. It's obvious that atheism entails nothing about gratitude. But, on its own, atheism also entails nothing about the overall goodness of the world. Atheism just asserts that a certain supernatural being doesn't exist. Since that being is supposed to be supremely good, atheism entails that this good is missing from the world. So atheism does have a certain 'negative' axiological commitment. But that leaves the question of the overall value of a godless world entirely open. ${ }^{16}$

Let us set aside the earlier worry that we have little evidence that many (or any) atheists endorse EO. It still seems odd to think that atheists who also accept EO must conclude that atheism is false if they accept the Bleak Upshot. If atheists discover that EE is in tension with EO, how could that be, on its own, a reason to conclude that the argument from evil, and their other arguments against theism, are mistaken? That would be like concluding, from a failed exam, not that you're not as good as you thought but that the teacher must be conspiring against you. In most cases, when we encounter strong evidence that things are worse than we had assumed, that's a bad reason to reject that evidence and hold on to our rosy assumption. To be motivated to adopt theism on these grounds would be an instance of wishful thinkingan epistemic vice. Moreover, it's a vice that atheists often accuse theists of succumbing to. So surely what atheists should conclude instead is that EO is false. ${ }^{17}$

We might be able to revive the argument by showing that there are independent grounds for holding on to EO. As an analogue, consider the moral argument for theism. One version of the moral argument goes roughly like this: atheism, it's argued, entails that there's no morality, but since we know with far greater certainty that e.g., torturing infants for fun is wrong than we know that any of the arguments for atheism are successful, we should reject atheism. Now there are many problems with this argument. But it has one major advantage over Nagasawa's argument. It's plausible that we can have a priori knowledge of basic moral propositions. But it's very hard to see how, on atheism, we could have a priori knowledge of 
the overall value of the world. The value of the world is a function of what's in it. And what's in our world is a contingent matter - and, as we shall soon see, we aren't in a position to know many of the relevant facts. ${ }^{18}$

\section{AS AN AXIOLOGICAL ARGUMENT}

I argued that even if the Bleak Upshot were true, this would give us no reason to think that atheism is false. I now turn to consider whether we should accept the Bleak Upshot. Moreover, even if we reject the argument's last step, the truth of the Bleak Upshot would still be important. It can potentially bear on questions relating to what has been called the axiology of theism: ${ }^{19}$ just as we may want to know whether or not God does exist, we may also wish to know whether, if atheism is true, things would be considerably worse in certain respects, or even overall bad. We may also wish to know what attitudes we should have towards the world, if we find that there is no God. Even if it would be an epistemic vice to be motivated to adopt theism just because atheism has bleak implications, it might be perfectly appropriate to ardently wish that God exists (or had existed).

Let us turn then to what I take to be Nagasawa's argument for the Bleak Upshot:

\section{The Axiological Argument from Evolutionary EviL}

(1) EE: Terrestrial evolutionary history contains a vast amount of badness.

(2) If atheism is true, nothing exists beyond the material universe.

\section{Therefore}

(3) If atheism is true, Axiological Optimism is (probably) false: the universe isn't overall good.

\section{Therefore}

(4) If atheism is true, Attitudinal Optimism is (probably) false: we shouldn't be thankful that we, and the world, exist.

Before considering this argument, it's worth noting that, if successful, this argument is likely to establish something stronger. According to the Bleak Upshot, atheism is likely to mean that the world isn't overall good, or merits our gratitude. This is compatible with the world having overall neutral value, being neither good nor bad. But it's unlikely that all the good and bad in it exactly cancel each other out. So it's almost certain that the argument should really support 
(3') If atheism is true, then Axiological Pessimism is (probably) also true: The universe is overall bad.

And if (3) supports (4), then (3') should arguably support

(4') If atheism is true, then Attitudinal Pessimism is (probably) also true: we should regret that we, and the world, exist.

I'll start by asking whether (1) and (2) can support such axiological conclusions. I'll later consider whether, if it did, the further attitudinal claims would follow.

Notice first that this argument purports to establish a categorical claim about the value of the world under atheism. Thus, when we consider the work (2) is doing in the argument, we need to bracket comparative claims to the effect that, e.g., it would be better if theism is true, or categorical claims about the value of the world under theism; atheism could entail that the world isn't good even if theism was somehow also incompatible with Axiological Optimism and even if things would have been even worse under theism. I'll therefore postpone discussion of these further axiological claims.

Now strictly speaking (2) isn't quite right. Atheism doesn't entail metaphysical naturalism and, conversely, theism is of course more than supernaturalism. But Nagasawa is obviously right that contemporary atheists are typically naturalists. Still, this means that the above argument can't show that atheism has bleak implications, only that naturalist atheism does. Moreover, this way of marking the axiological upshots of atheism doesn't engage with what is axiologically distinctive of the theist alternative- both positively and negatively. We'll return to this when we discuss the categorical axiological properties of theism.

More directly relevant for our current purposes is that (2) is merely a negative claim. It tells us nothing about the value that the world would contain if atheism is true. It just tells us that the only entities and properties which determine that value are those contained in the natural world. No supernatural cavalry can come to the rescue to redeem all those millions of years of agony. Still, in itself, that's neither bad nor good news - it may exclude God and His immense value, but also Satan and all kind of malignant supernatural forces.

So all the positive work must be done by (1). But while (1) is clearly true, and refers to a staggering amount of badness, there's plainly a vast gap between (1) and (3), since (1) refers 
only to the badness contained in what is a spatiotemporal part of the world (whether the latter is understood to refer to the cosmos as a whole or just to Earth). Moreover, (1) doesn't yet establish the overall value of that spatiotemporal region since it leaves it open that all that badness is counterbalanced or even outweighed by the good contained in this region. However, before we can consider these gaps in the argument, we need to get clearer about the nature of the natural evil to which (1) refers. In particular, we need to examine Nagasawa's claim that evolution involves a distinctive kind of 'systemic evil'.

\section{SYSTEMIC VS FIRST-ORDER EVIL}

Nagasawa argues that the 'cruelty of nature' raises a problem of evil that is 'fundamentally different' from more familiar formulations that focus on specific events, such as the Holocaust, or specific types of events (e.g. earthquakes or murder). By contrast, here we are considering an entire biological system that is 'fundamentally evil' because it

“... involves competition for survival. For approximately four billion years, uncountably many organisms have competed and struggled for survival. In this cruel, blind system, the weaker are eliminated, and even the survivors will eventually die, often painfully and miserably."20

And because this problem of systemic evil is focused on something more fundamental than specific events or types of events, it's more forceful than the standard problem.

The intended axiological import of these claims is unclear. Axiological Optimism makes a claim about the overall value of the world. It's not specific events or types of events that decide that value, but their aggregate. So what matters for that isn't a particular event of a sentient animal being devoured alive, or predation more generally, but the aggregate sum of the suffering that was endured over this immense period.

At least that is how such axiological questions would be typically addressed, and that's how I will understand evolutionary evil. But Nagasawa seems to have something else in mind. He may think that, because natural selection is the source of all that suffering, it's more fundamental. Of course, natural selection is causally more fundamental than its products. But that just makes it a prodigious instrumental bad. However, that's irrelevant: merely instrumental value adds nothing to the overall value of the world. (Cancer is similarly the causal source of an immense amount of suffering but only the suffering it produces matters 
intrinsically: the world would have been just as bad had that suffering been caused by something else.)

Now, on some views, acts of cruelty and injustice add to the badness of the world over and above their consequences. But although Nagasawa describes nature as cruel and unjust, these are surely merely metaphors, if atheism is true. Or perhaps the world is made worse by being causally wired up such that pain is its guaranteed product? I am open to this idea, though it involves a controversial value claim. But even if correct, it seems very doubtful that this badness is more significant than the first-order suffering itself. Otherwise it would be better if a world contained even more suffering if, say, that suffering was accidental and didn't have its source in such a biological system. This seems wrong. ${ }^{21}$

So the idea of systemic evil requires further clarification. In what follows I'll therefore focus on the aggregate of evolutionary suffering. But this seems to me to make the argument stronger, not weaker. And Nagasawa himself in fact repeatedly appeals to that first-order suffering. ${ }^{22}$

\section{EVOLUTIONARY EVIL AND THE GOODNESS OF THE WORLD}

The amount of suffering that is associated with natural selection, operating over hundreds of millions of years, is staggering. We can only respond to it with horror, even though our minds are too feeble to fully grasp suffering on such a scale. But all that natural evil, I said, doesn't even establish that

Evolutionary Pessimism: the overall value of terrestrial evolutionary history (excluding Homo sapiens) is negative (or not positive).

That would depend on whether that evil is outweighed by competing goods: there's pleasure and other positive affective states that most animals also experience, and perhaps also the value of the existence of sentient beings - as well as, on some views, of all living things in their immense variety.

Whether evolutionary history contains more bad than good is a difficult empirical question. However, several authors argue that the lives of most animals in the wild contain more bad than good. ${ }^{23}$ If this argument about suffering in the wild is correct then it could be generalised into a general claim about evolutionary history. ${ }^{24}$ 
But even that is just a claim about one part of the past. Once humans arrive on the scene, they potentially bring into play distinctive goods - such as the value of rational agency, moral virtue, deep personal relationship, knowledge, achievement and aesthetic creation and appreciation - that are widely held to possess far greater value than mere sentience. ${ }^{25}$ So to show even just that terrestrial history is overall bad until now, Nagasawa will need to show either that human history is itself overall bad, or that even if it's good, it's not enough to outweigh the prior bad. ${ }^{26}$

In passages that try to address something like this worry, Nagasawa tells us to suppose that

\footnotetext{
"positive things in the world and life are painted yellow, while negative things in the world and life are painted grey. Existential optimism says that although there might be parts of the world and people's lives that are painted mostly grey, overall the whole picture is painted mostly yellow"27
}

However, Nagasawa holds that natural selection reveals that "this perception of life and the world is inaccurate", and

"If a large part of the material universe and a large part of life in it are painted grey, atheists have to give up existential optimism, which entails that these components are painted mostly yellow." 28

This passage can suggest that Nagasawa is assuming a spatiotemporal understanding of 'overall value' (at least within the natural world) ${ }^{29}$ : we ask, of a given spatiotemporal part of the world, whether it's overall negative or positive, and then see whether the world is on the whole more positive or negative. And, indeed, since evolution has unfolded over billions of years, while human history is comparatively incredibly brief, then, if Evolutionary Pessimism is correct, then you can see why it might seem that the overall balance is negative.

But that would be a mistaken conclusion. To begin with, since most of the universe is basically empty, the universe itself is nearly entirely devoid of value (neither grey or yellow). So by this logic we should conclude that the world is neither good nor bad. More importantly, questions about overall value aren't concerned with whether things are positive/negative per square mile. A world in which billions feel utter bliss in one spot, and a handful feel mild agony in the rest of the world, would count as an overall bad place by this odd measure. 
Questions about overall value are concerned with the aggregate of value out there, not about its spatiotemporal spread.

Now while temporal and spatial spread are in themselves irrelevant, numbers do make a difference, and the number of sentient beings who had suffered greatly over many millions of years is mind-boggling. If Evolutionary Pessimism is true, and we're hedonists, that badness is likely to swamp whatever opposing good human history may contribute. But if we reject hedonism, and accept at least some of the non-hedonic goods I mentioned above, then answering the question of the overall value of terrestrial history so far would involve an enormous undertaking that is obviously beyond the scope of this paper. ${ }^{30}$

In any event, even if we arrive at a grim answer to that question, this won't begin to settle the question of the overall value of the world as a whole. For there is, to begin with, our own future. Humanity might go extinct soon or go on for many millions of years. The future may be utopian or dystopian or anything in between. We simply don't know. And if we have in mind the universe as a whole, the Earth is anyway an incredibly tiny part of that. Now, if we're alone in the universe then and sentient beings are the only source of value, then this doesn't matter: whatever conclusions we reach about the Earth also apply to the universe as a whole. But these are large assumptions. For all we know, there may be a multitude of advanced intergalactic civilizations, meaning that what happens on little planet Earth is of negligible significance in deciding the value of the universe as a whole. Nagasawa could reply that all sentient and rational beings in a naturalist framework must be products of natural selection and, therefore, if there's life elsewhere that just massively adds to the overall amount of evil. But this assumes that evolution cannot take more benign forms in profoundly different contexts. And even if evolution does operate in similar ways everywhere, it's less likely that all rational beings produced by evolution must be similar to us. So whatever conclusions we reach about the case of the Earth cannot be assumed to generalise. Since we are clueless about the answer to all these questions about the future, and life outside the Earth, we simply aren't in a position to even guess whether Axiological Optimism is true, on atheism, at either the terrestrial or cosmic level. ${ }^{31}$

\section{ATHEISM, PESSIMISM, AND GRATITUDE}

It remains true that, if Evolutionary Pessimism is correct, then there's a massive axiological deficit that needs to be overturned to avoid global pessimism. While we're not remotely in a position to know that, it's perfectly possible that things will overall turn out 
bad. Now that would be a depressing fact about the universe. But it's not obvious that this should drive us to despair. Now more familiar pessimist views, such as Schopenhauer's or Benatar's, also make such a claim about the world as a whole. ${ }^{32}$ But they arrive at that general claim via the claim that human lives are overall bad, perhaps even inescapably so. The kind of pessimism we're considering is different: that even though our own lives are going reasonably well, this good is just a part of a whole that is overall bad. ${ }^{33}$

As I pointed out earlier, people rarely orient their lives in relation to such grand axiological questions. Nor would accepting global pessimism force us to change how we live. It's hard to see, for example, why it would undermine morality, or make our personal projects pointless. And our acts could still make the world as a whole better, perhaps even make a great difference; though it would sadly also be true that even if we all did our best, at most we could make the world less awful. ${ }^{34}$

Global pessimism may dampen our motivation but it needn't change what we do. Should it, however, change how we feel? Nagasawa's argument assumes that, if Axiological Optimism is false, we shouldn't feel thankful that we, and the world, exist. But the relation between axiology and attitudes such as gratitude is more complex than that.

We should first consider the falsity of axiological optimism. If optimism is false, the world isn't overall good. But if the world has neutral value, then it's not bad either. We can say, of such a world, that it's neither better, nor worse, than nothing. By contrast, if global pessimism is true then the world is worse than nothing. It would have been better if the world didn't exist, or at least if sentient life never emerged within it. That's a bleak view.

Still, how this should affect our attitudes depends on which perspective we adopt. When we consider things from the point of view of the universe, as Sidgwick famously put it, then we should respond with indifference to a universe with neutral value, and with sadness to one with negative value. Attitudes such as gratitude or regret, however, essentially involve a comparison with some alternative, so how we should feel about the world, even from such a lofty standpoint, depends on what is the relevant alternative. However, that alternative needs to be broadly realistic: it makes no sense to feel deep gratitude that, say, I wasn't kidnapped by malevolent extra-terrestrials. ${ }^{35} \mathrm{I}$ argued earlier that even if the world is overall bad, this doesn't give us a reason to reject atheism. But if theism isn't a realistic alternative from an atheist standpoint, then neither can it motivate regretting that God doesn't exist (though it may motivate preferring His existence).

The naturalist framework does offer more realistic alternatives. For example, if the very emergence of sentient life is extremely unlikely, then a lifeless universe would be such an 
alternative. So if global pessimism is true, we should regret, from such a cosmic standpoint, that sentient life ever emerged (though if the world has merely neutral value this contrast doesn't really matter).

We rarely, however, see things from such a high altitude. When we are glad about our own lives, or the lives of those we care about, we do so from our own personal standpoint. Still, we want such partial attitudes to be morally defensible. Now, if our own lives are good, and the falsity of Axiological Optimism just means the world has neutral value, then I see no problem in being unreservedly glad that we exist. If the alternative is nothing of value, why not prefer the current world, which has the same overall value, but also contains $u s$ ?

It's less obvious how we should feel if our own lives are good yet the world around us is awful. If, for example, life will inevitably emerge somewhere in our universe, with evolutionary evil in its wake, then there's no realistic impartially better alternative, and we can again be defensibly glad that, out of this range of awful options, at least the one that contains us was realised. And we can be even more clearly glad that we exist if the closest alternatives were ones with evolutionary evil but where no intelligent species evolves. If, however, life is a rare and contingent thing, and an utterly lifeless universe was in the offing, then it's harder to hold, as our all-in attitude, a preference for this awfulness just because, within it, we are nevertheless having a good time. But even this doesn't mean we can't be glad we exist. It just means our gladness shouldn't be all-in. ${ }^{36}$ It needs to be conditional: given that things have gone so badly, we are still personally pleased that, against the odds, we somehow still arrived and are doing reasonably well. While such gladness is conditional, it can still be deep and heartfelt. Indeed, most instances of gladness implicitly have that structure. And dark surroundings often amplify, rather than dampen, the gladness we feel about glimmers of good.

So lack of overall good, and even overall badness, are perfectly compatible with justified gladness about what's still good. But it's worth noting that overall value and attitude can also come apart in the other direction. For something to be overall good is a low bar. There are few people whose lives are so bad that they aren't even worth living. Yet that hardly means that virtually everyone should be glad about their lives. Most of us will insist that a life that has just a little bit more good than bad just isn't good enough. That can also be true of the world as a whole: if good just barely edges out the bad, that's hardly cause for celebration. It may still make for a very disappointing world. ${ }^{37}$

Let me end this section by briefly considering a strand of Nagasawa's discussion that I've deliberately avoided so far. Nagasawa draws parallels between his 'existential problem 
of evil' and Janna Thompson's 'apology paradox'. ${ }^{38}$ Suppose a country apologises for, say, injustices committed in its colonialist past. To sincerely apologise for such injustices is presumably also to regret them, to wish they never happened. Yet if history had been better in this way, neither we, nor the descendants of the victims of such injustices, would have come to exist. So such apologies seem to conflict with our gladness that we, and those we care about, exist.

Nagasawa is correct to see a parallel between the dependence of our individual existence on past injustice and the dependence of our existence, and of that of humanity as a whole, on the occurrence of evolutionary evil. So there's a similar tension between regretting evolutionary evil and being glad that we exist.

However, when Nagasawa writes that the thrust of his argument is the question

"Why should we think that the world is overall good and that we should be happy and grateful to be alive in it if our existence depends fundamentally on a violent, cruel, and unfair biological system which guarantees pain and suffering for uncountably many sentient animals?", 39

he is, I believe, conflating two distinct issues. While the existence of great past evil obviously bears on the question of whether the world is overall good, our dependence on past evil doesn't. To see this, consider on the one hand that the world might be an overall bad place even if our existence in no way depended on any past suffering or injustice (imagine, for example, that we humans are the product of an intervention by extra-terrestrials). On the other, our existence would depend on all that past suffering even if the world as a whole is a wonderful place. Indeed, this dependence could be troubling even if the value we humans bring about massively outweighs the badness in the evolutionary past. So although both kinds of considerations seem to challenge our gladness that we exist, they are distinct. Since I've touched on the issue of our dependence on past sentient suffering elsewhere, ${ }^{40}$ I'll set this aside here.

\section{CATEGORICAL VALUE AND THE AXIOLOGY OF THEISM}

In recent years, there has been increasing interest in axiological questions about theism. That discussion asks, not whether God exists, but whether it would be better if God exists, with pro-theists holding that it would be, and anti-theists arguing that God's existence would rather makes things worse. ${ }^{41}$ The axiological claims we have been considering, however, 
involve value claims that are importantly different from the ones the debate in the axiology of theism has so far focused on. Whereas that debate has focused on comparative value-on relations such as better, worse, or equal — here we have been discussing categorical valuegood, bad or neutral.

This difference is significant in several ways. First, the axiology of theism has typically assumed a fairly mild view of atheism. Even pro-theists assume, at least implicitly, that things can be fairly good if God doesn't exist. They just argue that they'll be far better if $\mathrm{He}$ does. But Nagasawa's argument for what I called the Bleak Upshot makes a more ambitious claim: that things might be positively bleak if God doesn't exist, not merely inferior. Many people will shrug at the obvious point that things aren't perfect; we can still be, and perhaps should be, perfectly satisfied if the actual world is good enough. This won't be so if the world is positively bad. Second, one worry about the project of the axiology of theism is that God is supposed to be a necessary being. Some worry that this means that, if God exists, to compare it with the atheist alternative is to compare it with an impossibility. ${ }^{42}$ Conversely, if the very idea of God is incoherent, as some atheists argue, then there again seems to be no viable alternative to atheism. By contrast, the kind of categorical argument we have been considering would go through whether or not there's a viable theist alternative.

We can still ask, however, how such a categorical argument, if successful, would link with the more widely discussed comparative questions. Suppose that, if atheism is true, the world as a whole is overall bad. If the theist alternative is good - even minimally good - this would entail what is known as wide impersonal pro-theism, the claim that the world as a whole would be overall better if God exists. And of course it would give us powerful impersonal reasons to want God to exist (or to have existed). ${ }^{43}$

Still, that would follow only if we can show that, had God existed, the world would be overall good. So I now turn to the question of the categorical value implications of the truth of theism.

\section{THE CATEGORICAL VALUE IMPLICATIONS OF THEISM}

Nagasawa's core argument claims that if God doesn't exist, then the world (probably) isn't overall good. As we just saw, this is silent on whether

Theist Optimism. If God exists, then the world is overall good. 
But Nagasawa suggests that, although the evil associated with evolution should also trouble theists, they are in a much better position to hold on to Existential Optimism. He highlights, as we saw earlier, that theism offers a transcendent realm, and wider ontology, that could provide the materials to overturn whatever badness reigns in the natural world. But, to repeat, this is compatible with that transcendent realm making things even worse. Nagasawa does also mention more distinctive aspects of theism - the afterlife, and of course the existence of a perfectly good, omniscient and omnipotent being, though he doesn't spell out their axiological import. But it's plausible that if God is the perfect being, God adds superlative, likely infinite value to the world. And an eternal, blissful afterlife also seems to contribute infinite good both to each such blissful life, and to the world as a whole. Nagasawa doesn't mention that, in addition, if God's existence entails that every evil that occurs only does so because it's necessary for some greater good, then all the evils we see around us, including evolutionary evil, are of necessity outweighed by greater goods. ${ }^{44}$ If so, then it seems that a theist world would, of necessity, be not just good, but supremely or even infinitely good.

However, another thing that Nagasawa doesn't discuss is the possibility that God's existence has distinctive downsides, as anti-theists argue. Unless such downsides are ruled out, then the goods entailed by God's existence cannot, on their own, decide the world's overall value. For example, your eternal bliss in the afterlife might be outweighed by the badness of the never-ending violation of your privacy. ${ }^{45}$ If so, then under theism the world might not be an "overall good place".

This may seem surprising. After all, Leibniz famously argued that God created the best of all possible worlds, and even those who reject this claim assume that God must create a world that's at least good enough. Notice, however, that if we admit 'atheist' worlds into the space of possible worlds - as Nagasawa's argument assumes — then Leibniz's claim is misleading: since God cannot create such atheist worlds, the claim should really be that God created (or would have created) the best of all the possible worlds available to Him. But on either reading, Leibniz's comparative claim entails nothing categorical about the world that God will create: Nozick tells the old joke about the optimist who says this is the best of all worlds; the pessimist agrees. ${ }^{46}$ The best might still be bad.

Why, however, would God create a world, if that world isn't good? To begin with, atheists needn't accept that, had God existed, He would have created anything. Second, God having good reason to create the world only requires that a world containing only God is no 
better, or worse, than God plus the (or a) world; and the latter might still be bad (or no good), even if better. ${ }^{47}$

I concede that Theist Optimism is plausible. But this must be defended as a substantive value claim. It's not simply entailed by the concept of God. ${ }^{48}$

\section{CONCLUSION}

Atheists typically see the theory of evolution as offering strong support to their position. It helps them reply to the argument from design and, because the evolutionary process involves a staggering amount of senseless suffering over many millions of years, it is also seen as greatly bolstering the argument from evil. But that mass of past suffering remains even within the atheist framework, and in my view Nagasawa is quite right that atheists tend to overlook its significance. We cannot be outraged by the idea that a benevolent god would allow such suffering to go on yet forget all about it the moment we've concluded that God doesn't exist. Nagasawa sketches an intriguing challenge to atheists: the natural evil associated with evolution, he suggests, is incompatible with optimism about the world, and with the kind of gratitude about one's existence that many atheists feel. I have argued here that, first, even if the evil associated with evolution is incompatible with such optimism, this gives us no reason to accept theism. Second, while there is at least an empirical case to be made that terrestrial evolutionary past was overall bad, this is not sufficient ground for rejecting axiological optimism in any broader sense. Third, even if we were forced to reject such axiological optimism, this needn't have much effect on our lives, nor prevent us from feeling gratitude for them. However, while I have argued that Nagasawa's argument is unsuccessful as it stands, I have also suggested that it offers a promising model for a distinctive kind of categorical axiological argument that has not yet been discussed so far in the ongoing debate on the axiology of (a)theism. Just as we can ask whether it would be better, or worse, if God exists, we can also ask whether if God exists (or doesn't exist) the world would be overall good or bad. The gruesome evolutionary past cannot decide such questions on its own. But it will play a large role in any serious attempt to answer them. ${ }^{49}$

\section{REFERENCES}

Benatar, D. (2006). Better Never to Have Been. OUP.

----. (2015). 'The Misanthropic Argument for Anti-Natalism'. In S. Hannan, S. Brennan, and R. Vernon (eds.), Permissible Progeny? The Morality of Procreation and Parenting. OUP.

----. (2017). The Human Predicament. OUP. 
Dawkins, R. (2010). 'The Greatest Show on Earth.' Paper delivered at the University of Auckland, New Zealand, 13 March. https:// www.alumni.auckland.ac.nz/en/photo-galleries-andvideo/public-lectures/ richarddawkinsthegreatestshowonearthlive/ richarddawkinsthegreatestshowonearthlive-1.html

Horta, O. (2015). 'The Problem of Evil in Nature: Evolutionary Bases of the Prevalence of Disvalue', in Relations. Beyond Anthropocentrism, 3, 1

Hurka, T. (2000). Virtue, Vice, and Value. Oxford: Oxford University Press.

Kahane, G. (2011). 'Should We Want God to Exist?', Philosophy and Phenomenological Research, $82,674-696$.

Kahane, G. (2019). 'History and Persons', Philosophy and Phenomenological Research, 99, 1: 162187.

----. (forthcoming-a). 'Is the Universe Indifferent? Should We Care?', Philosophy and Phenomenological Research.

----. (forthcoming-b). 'The Significance of the Past', The Journal of the American Philosophical Association.

Kraay, K. ed. (2018). Does God Matter? Essays on the Axiological Consequences of Theism, Routledge.

Kraay, K. and Dragos, C. (2013). 'On Preferring God's Non-existence', Canadian Journal of Philosophy, 43, 157-178.

Lougheed, K. (2020). The Axiological Status of Theism and Other World Views. Plagrave.

Miele, Frank. (1995). 'Darwin's Dangerous Disciple: An Interview with Richard Dawkins', Scepsis 3, 4. https://scepsis.net/eng/articles/id_3.php/.

Nagasawa, Y. (2018). 'The Problem of Evil for Atheists'. In Trakakis, N. N., ed., The Problem of Evil: Eight Views in Dialogue. OUP.

Ng, Y.-K. (1995). “Towards Welfare Biology: Evolutionary Economics of Animal Consciousness and Suffering”. Biology and Philosophy 10 (3): 255-85.

Nozick, R. (1989). The Examined Life. Simon and Schuster.

Parfit, D. (2011) On What Matters, vol. II, OUP.

Prescott, P. (2021). 'The Secular Problem of Evil: An Essay in Analytic Existentialism', Religious Studies, 57: 101-119.

Schopenhauer, A. (1969). The World as Will and Representation. Vol. II, Courier Dover.

----. (1976). Essays and Aphorisms.

Thompson, J. (2000). 'The Apology Paradox', The Philosophical Quarterly, 50.

Tilley, T. W. (2018) 'Response to Nagasawa', in Trakakis, N. N., ed., The Problem of Evil: Eight Views in Dialogue. OUP.

Tomasik, B. (2015). 'The Importance of Wild-Animal Suffering'. Relations. Beyond Anthropocentrism 3.

Wallace, R. J. (2013). The View from Here: On Affirmation, Attachment, and the Limits of Regret. Oxford University Press.

\footnotetext{
${ }^{1}$ Nagasawa (2018).

${ }^{2}$ For my purposes, metaphysical naturalism can be broadly defined as the view the ontology of natural science exhausts what concretely exists. I'll also understand theism in a standard way as claiming that there exists a perfectly good, omniscient and omnipotent being who is the creator of the universe; I'll simply assume that naturalism entails the falsity of theism.
} 


\footnotetext{
${ }^{3}$ Dawkins (2010).

${ }^{4}$ Miele (1995).

5 Ibid., 151.

${ }^{6}$ Ibid., 156.

${ }^{7}$ Ibid., 161-162.

${ }^{8}$ Ibid. 162-3.
}

${ }^{9}$ When we describe something as overall good, we typically mean that the good in it outweighs the bad, and this is also the most familiar philosophical understanding of both 'an overall good world' and 'optimism'. Moreover, it's hard to think of a sense of 'overall good world' that won't at least also imply that the world is overall good in this literal sense. Nagasawa cannot just mean that the world doesn't contain terrible things, or the assumption that natural causal forces tend to the good. No educated person would seriously entertain these claims and atheists regularly appeal to contrary claims in arguing against theism — as Dawkins repeatedly does in print. ${ }^{10}$ See Schopenhauer (1969), 576.

${ }^{11}$ Ibid., 154.

12 Ibid., 155.

13 Ibid., 156.

${ }^{14}$ Such agnosticism is endorsed by Derek Parfit—hardly a pessimist—one of the few atheist philosophers to explicitly discuss this question (see Parfit, 2011, 607ff).

${ }^{15}$ While this is my reading of Nagasawa's challenge to atheism, for simplicity I'll refer to it as Nagasawa's argument.

${ }^{16}$ Some philosophers, and many theists, argue that atheism entails value nihilism. And that would trivially entail the falsity of axiological optimism. But if nihilism is true then, of course, one couldn't support that conclusion by appealing to evolutionary evil — that claim would also be rendered false by nihilism, which also rules out axiological pessimism - my main focus here.

${ }^{17}$ They could also, less plausibly, opt to reject EE or even hold on to atheism but reject naturalism - atheism is compatible with numerous supernaturalist and idealist views.

${ }^{18}$ Nor is it plausible that EO is some kind of non-negotiable pragmatic commitment that is presupposed by our core practices. Setting aside that it's doubtful that we should form views about the world on the basis of pragmatic commitments, surely nothing we do presupposes a view about the overall value of the universe.

${ }^{19}$ See Kahane, 2011; Kraay \& Dragos, 2013; Kraay, 2019; Lougheed, 2020.

${ }^{20}$ Ibid., 151. Though sentient beings are likely to have emerged only about 500 millions years ago, and possibly significantly later.

${ }^{21}$ For further discussion see Kahane (forthcoming-a); for an account of why we should even care about distant past evil, see Kahane (forthcoming-b).

${ }^{22}$ See e.g. ibid., 157.

${ }^{23}$ See Ng (1995), Horta (2015); Tomasik (2015).

${ }^{24}$ I further develop this argument in unpublished work.

${ }^{25}$ Tilley (2018) gestures at this issue but he combines it with the less plausible suggestions that suffering that leads to great good isn't really an evil, and that animals suffering is only of minimal import. I reject both claims.

${ }^{26}$ I take no stand here as to whether we humans might improve the situation or make it even worse. For the former view, see Parfit (2011), 607ff; for the latter, see Benatar (2015).

${ }^{27}$ Ibid., 159-160.

28 Ibid. 161.

${ }^{29}$ It's unclear how the picture metaphor would be extended to the supernatural domain if it's not understood in spatiotemporal terms.

${ }^{30}$ I have tried to sketch what such an undertaking would involve in unpublished work.

${ }^{31}$ In personal communication, Nagasawa denies that he understands Existential Optimism to apply on the cosmic scale. The claim that the world is good is meant only to apply to "that part of the world that is sufficiently relevant" to us. But for many, the relevant part of the world would be the current world, or perhaps recent human history, making the evolutionary past irrelevant. And my criticism here would anyway apply even if we focus just on overall value of things on Earth, or even just (and rather arbitrarily) on terrestrial history till now. Moreover, if the terrestrial context turns out to be an unpleasant aberration, and there are millions of 
prospering galactic civilizations who are, in addition, the product of a fairly benign evolutionary process, it would be rather odd for (terrestrial) atheists to complain that the world isn't a good place.

${ }^{32}$ See Schopenhauer (1969), (1976); Benatar (1917).

${ }^{33}$ Prescott (2021) has recently argued, in line with Nagasawa, that atheists also face a distinctive problem of evil. However, Prescott is concerned with evil that is supposed to be inherent in the human condition, not with the kind of global pessimism that is our concern here - a form of pessimism that's driven by badness residing in non-human lives.

${ }^{34}$ See Parfit (2011), 607ff.

${ }^{35}$ See Hurka (2000), 118 as well as Wallace (2013), $72 \mathrm{ff}$.

${ }^{36}$ See Wallace (2013).

${ }^{37}$ Also relevant here is Benatar's distinction between lives not worth living and lives not worth creating (See Benatar, 2006). Even if a life contains overall more good than bad, it might still contain awful suffering, or just too little good.

38 Thompson (2000).

${ }^{39}$ Ibid., 156.

${ }^{40}$ See Kahane (2019), especially pp. 22.

${ }^{41}$ See the references in fn. 19.

${ }^{42}$ For discussion and response to this worry, see Lougheed (2020), pp. 8-16.

${ }^{43}$ Though distant evolutionary evil is unlikely to bear on the 'personal' question of whether God's existence is good for each of us.

${ }^{44}$ See Kraay \& Dragos (2013).

45 See, e.g., Kahane (2011); Lougheed (2020).

${ }^{46}$ Nozick (1989).

${ }^{47}$ Though the downsides that anti-theists have so far associated with God's existence admittedly won't apply if only God had existed.

${ }^{48}$ Even if, if God exists, Axiological Optimism would be true, an argument to the effect that Axiological Pessimism is true of the natural world may give us further reasons for doubting that God exists. Such Pessimism would, for example, cast doubt on 'fine-tuning' considerations as reasons for thinking the universe was created by a benevolent as opposed to malevolent deity, and it would further bolster the traditional argument from evil. But developing this suggestions is beyond the scope of the present paper.

${ }^{49}$ I am very grateful to an anonymous referee and especially to Yujin Nagasawa for extremely helpful comments on a previous version of this paper. 